\title{
The challenge of fracture management in osteoporotic bones
}

L. N. Gakuu, MBChB, MMed (Surg), FCS (ECSA), Associate Professor, Department of Orthopaedic Surgery, College of Health Sciences, University of Nairobi, P. O. Box 19676 - 00202, Nairobi, Kenya. Email: menelik@africaonline.co.ke

\begin{abstract}
Objective: To determine the types of fractures encountered in osteoporotic patients and assess the functional outcome of these fractures. Also suggest change of their management and to suggest preventive interventions.
\end{abstract}

Design: A retrospective analytical 10 years study between 1998 and 2007.

Setting: The patients were treated at three private hospitals in Nairobi, Kenya.

Patients and methods: Consecutive files of traceable patients who were treated for osteoporotic fractures from January 1998 to December 2007. The demographic data, investigations, management methods and functional outcomes of the treatment were determined. The data collected was analysed using SPSS 17.0 windows.

Results: Sixty patients were available for review. Forty five were females while 15 were males, giving a F:M ration of 3:1. There were 14 vertebral fractures, 15 hip fractures ( 5 neck fractures intra-capsular) and 10 extra capsular)., 5 fractures of the distal wrist and 8 humeral fractures, 4 rib fractures, 6 pelvic fractures, 2 sternal fractures and 6 tibial fractures. Twenty six $(40 \%)$ of the above fractures namely the vertebral, ribs, pelvis and sternum were treated conservatively while 34 fractures $(60 \%)$ were treated by various methods of internal fixation. All were old patients aged 60 to 101 years (Mean 75 years.) The overall results of the surgery was unsatisfactory in $13(38 \%)$ due to metal pull out, screw loosening, periprosthetic fractures, none union seen in patients of hip, humerus, tibia fractures. Twenty one patients $(62 \%)$ had good outcome.

Conclusion: Osteoporotic fractures are a challenge to orthopaedic and trauma surgeons due to unpredictable results of surgery in the elderly patients.

Recommendations: It is suggested to make awareness among health workers especially the orthopaedic and trauma surgeons, nurses and physiotherapists so as to put preventive measures in place. As regards operative management careful planning as team work and use of newer techniques, pharmaceuticals like diphosphonates to assist in fracture healing and use of augmentation techniques is worthwhile considering. Kenya Orthopaedic Association (K.O.A) formulate a policy for management of osteoporotic fractures in our local set up.

\section{INTRODUCTION}

Osteoporosis is defined as a systemic skeletal disease characterised by low bone mass and micro-architectural deterioration of bone tissue with consequent increase of bone fragility and susceptibility to fractures (1). Osteoporotic fractures are associated with low impact trauma or even atraumatic. The diagnosis is both clinical and radiographic based on bone mineral density $\mathrm{BMD}$; low
BMD leads to fractures (2). In 1994 the World Health Organization (WHO) provided a platform to base operational definitions in four groups of (i) normal, (ii) Low bone mass (Osteopenia), (iii) Osteoporosis (iv) established severe osteoporosis with presence of one or more fragility fractures (3).

The commonly reported fractures are of the hip, vertebra and wrist $(4,5)$. However, osteoporosis is a systemic skeletal disease and other fractures occur in the humerus, ribs, tibia, foot, pelvis and knee (5-8). 


\section{MATERIALS AND METHODS}

Files of patients treated for various fractures due to osteoporosis were reviewed and examined for the fracture sites, the treatment and outcome.

The different modes of treatment were analysed. All patients were given biphosphates, vitamin D and calcium supplements. All operated patients received intra-operative intravenous prophylactic antibiotics of rocephin 1gm. The patients with vertebral fractures, pelvic fractures, hip fractures and leg fractures all received prophylaxis against venous thromboembolism (VTE) by $40 \mathrm{mg}$ subcutaneous clexane, compressive stockings and physiotherapy and early mobilization as soon as tolerated.

The existing co-morbidities were analysed and documented. Union of the fractures was assessed by serial X-rays at intervals on appointment and followed up for a minimum of 24 months (median 60 months) range 2 years to 10 years. Any complications were recorded in patients files and followed up on appointed dates.

\section{RESULTS}

There were 60 patients whose files were available. Forty five were post-menopausal women and fifteen were males giving a female-male ratio of 3:1. The patients were all elderly patients aged 60-101 years (mean 75). The anatomical site of the fractures were 14 vertebral fractures, 15 hip fractures (5 intracapsular) and 10 extracapsular), 5 distal radius fractures (colles fractured), 8 humerus fractures, 4 rib fractures, 6 pelvic fractures and 2 sternum fractures. The mode of treatment given was 26 (43\%) fractures were treated conservatively by bed rest, medications and follow-up with serial check X-rays. These were all fractures of the vertebra, ribs, pelvis and sternum.

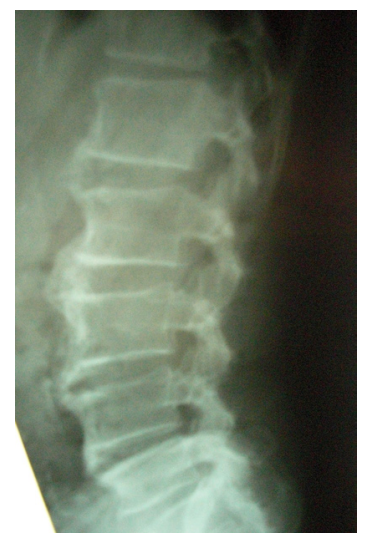

Figure 1: Osteoporotic lumbar spine showing collapsed L5 vertebra
The rest 34 (57\%) fractures were treated surgically. Twenty one patients (62\%) had good results but 13 (38\%) had poor results associated with metal loosening, screw pullout, pseudo-hip fractures; leading to revision surgery as detailed below (Figure 1):-

Hip fractures: There were 15 hip fractures, 5 intracapsular and 10 extra capsular. The intracapsular hip fractures were treated by cemented hip arthroplasty in four patients. The fifth patient was treated by none cemented total hip arthroplasty. She had reacted to bone cement in a previous hip surgery on the other hip.

The outcome of the hip arthroplasty was good in three patients with only one who developed protrusio acetabulum at 24 months post operative.

The extra capsular fractures were treated by fixation with dynamic hip screw (DHS) in six patients, proximal femoral nail PFN in two patients and angled plating in two patients. The functional outcome based on HARRIS SCORE (9) was good in five patients (4 DHS and 1 PFN) while poor in five patients of 2 DHS, 1 PFN and both angled plates due to loosening of the screws and metal breakthrough leading to pseudo arthritis. The hospitalization time ranged from 14 to 45 days (median 21) (Figure 2).

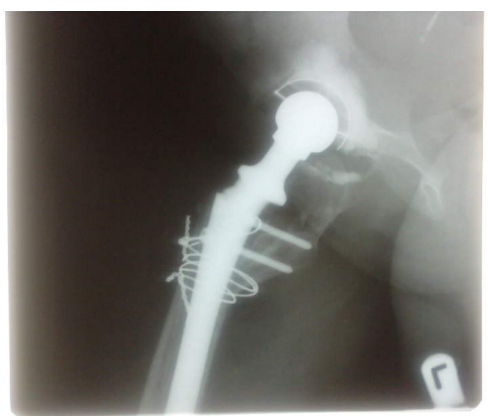

Figure 2: Peri prosthetic fracture in an osteoporotic patient

Humerus: There were eight humeral fractures four proximal and four distal. The proximal fractures were treated by T-buttressing plate and bone grafting. Two attained full union by sixteen weeks but two had poor results with complete loosening of the metals which needed revision surgery and augmentation with bone grafting and cerclage wiring in one patient and double plating in the other patient. The distal humeral fractures were treated by hybrid fixation with K-wires, contoured plates and bone grafting in three patients with healing and with good functional outcome. The fourth patient was treated by contoured plate but had complete disruption and loosening of the construct 
which needed revision, bone grafting with eventual healing but poor functional outcome due to limitation of elbow movements. The duration of immobilization in backslab for the distal humeral fractures was 10-21 days. The functional outcome was graded as excellent, good and poor using The MAYO Elbow Score (10). Postoperative complications were recorded on basis of file findings, review all X-rays AP/lateral views and clinical findings (Figure 3).
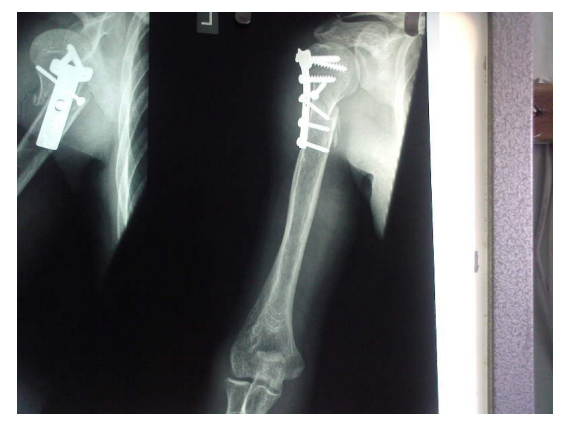

Figure 3: Osteoporotic fracture proximal humerus with loosening plate

Wrist fractures: There were five wrist fractures (Colles fractures). These were treated by manipulation and $\mathrm{K}$-wiring in three patients and Volar plate and K-wires in two patients. The plated fractures proceeded to heal satisfactorily by sixteen weeks. However, the three patients with K-wires had residual deformities with obvious dorsal deformities but clinically the functional outcome was acceptable. There was one complication of pin tract infection which cleared with dressings and appropriate antibiotics as per culture sensitivity (Figure $4 a-b$ ).

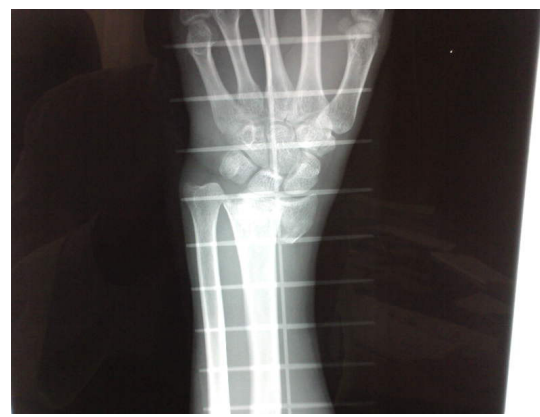

Figure 4a: Colles fracture of a 65 year old lady

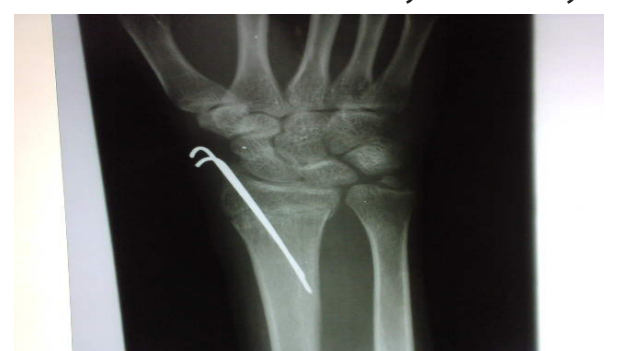

Figure 4b: Osteoporotic colles fracture treated by 2-K-wires. AP view
Tibial fractures: There were six fractures of the tibia two proximally and four at the ankle level. The proximal fractures were treated by buttressing T-plates and bone grafting. The outcome was good with healing at 14 weeks. The four ankle fractures were treated by immediate reduction imobilisation, elevation to minimise pain, swelling and pressure of the skin which was of poor texture in these elderly patients. The goal was to restore normal tibial-talar anatomy. This was obtained by correcting the fibular shortening and malrotation and ensure it sat on its incisural notch. The fractures were fixed with third tubular plate and lag screws. The healing occurred in two patients but two developed loosening of the metals and needed revision. One patient complicated with superficial infection which settled within one week (Figure 5).

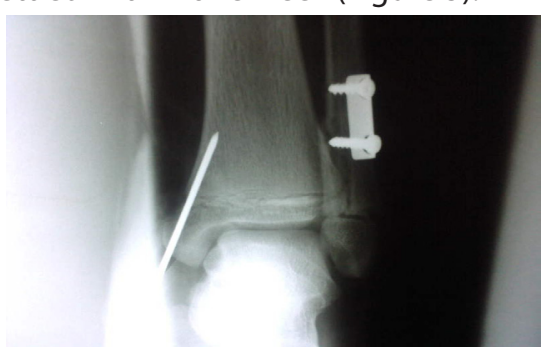

Figure 5: Distal tibia-fibula osteoporotic fracture fixed with plate and K-wire.

Co-morbidities: The existing co-morbidities were analysed. All the patients had co-morbidity mainly hypertension 55 , diabetes mellitus 45 , dyspepsia 25 , varicose veins 18 , Bronchial asthma 15 , obesity 10 , eczema 8 , renal insufficiency 5 , dementia 5 .

\section{DISCUSSION}

Osteoporotic fractures are difficult to manage and are associated with high rates of complications leading to poor results. Osteoporotic fractures impair patients function and quality of life in these elderly patients.

This review shows a high failure rate of 13 (38\%) of the operated patients due to metal pullout, breakthrough and eventually disintegration of the constructs leading to none unions, pseudo-arthritis and needing revision surgery. This phenomena has been reported in literature with rates of upto $50 \%$ failure rate. $(11,12)$.

This is due to poor screw anchorage in osteoporosis because of decrease of bone stock. Delayed union is also due to delayed callus formation and poor development of mature bone which incidentally has also been noted to have poor mechanical property (13). 
Osteoporotic fractures are common in the elderly especially post menopausal women as seen in this review of predominantly 45 females as opposed to 15 males with age ranging from 10-101. This has been noted in other series (14).

The treatment of osteoporotic fractures remains an unsolved problem. Healing may be improved by grafting as noted in the humeral, femoral and tibial fractures which mostly healed well when grafted in this review. However, this means further surgical procedures in an elderly patient who has multiple morbidity as seen in this review where all the patients have co-morbidities and the bone available for grafting is of poor quality and is limited (15-17).

It is suggested newer methods of improving bone healing be researched such as synthetic bone grafts or gene therapy for future research.

Osteoporotic fractures are a big challenge to the orthopaedic and trauma surgeon. The surgeon must realise that these fractures behave differently from the none osteoporotic fractures due to the very nature of osteoporosis. Osteoporosis leads to decreased cortical thickness, increased porosity of the cortex and rarefaction of the trabeullar network. This definitely affects the fixation strength and primary stability of implants (18) hence the large percent of screw loosening as seen in $13(38 \%)$ of metals in this review.

Osteoporotic patients also have changes in bone remodeling and decreased sensitivity to osteoblasts thereby leading to delay in fracture healing and causing implant instability. Osteoporotic fractures should therefore be treated as different from those of healthy bones. As seen in this review, osteoporotic fractures in specific areas of the hip, humerus and wrist have high risk of poor functional outcome due to high rate of implant failure (38\%). This has been observed in other series $(9,19,20)$.

In hip intracapsular fractures cemented arthroplasty is the gold standard as evidenced by good outcome in 3 out of 4 patients with only one getting protrosio-acetabulum. There is a high failure rate of osteosynthesis $(21,22)$. However impacted and none displaced fractures of the femoral neck with good interfragmentary contact can be treated by dynamic hip screw (DHS). DHS allows femoral neck to slide on a parallel track towards the femoral neck and allows buttressing. Fixation with a larger implant is more stable due to better axial loading (23). Additional lag screws to prevent rotation gives an even better stabilization (23).
The extracapsular fractures treated by DHS progressed better than angled plate patients who had complete metal breakthrough and also one proximal femoral nail (PFN) also behaved the same. Literature review shows osteoporotic humeral fractures are difficult to treat and various recommendations range from conservative treatment to open reduction and internal fixation and elbow replacement (24-26). Elbow immobilization for more than two weeks is discouraged (27-32) since upto $30 \%$ develop complications (20). Conservative treatment is to be avoided as it has poor outcome (34-36) due to stiffness as reported by Pereles et al (28) who reported good results of surgery and Rose et al (7) who had $85 \%$ good and very good results.

In our series the eight humeral fractures fared well with open reduction, fixation and bone grafting but three needed revision with hybrid fixation and bone grafting.

It is unclear which is the optional treatment for proximal and distal humeral fractures of osteoporotic fractures. Best outcome will depend on reduction and stabilization by balanced osteosynthesis adapted to weak bones. Bulky stiff hardware should be avoided as they may cause further fractures below the plates. Use of locking screws have improved the outcome in osteoporotic humeral fractures. Residual elbow stiffness (37-39), is a problem to many surgeons and same been reported elsewhere (40).

The three wrist fractures treated by wiring healed well but with deformity due to subsidence of the fractures. However, the functional outcome was good with relatively pain free wrist, and acceptable range of movement. Young 2000 reported good functional results despite poor X-ray appearance (42). Displaced fractures of the radius are generally unstable and cast immobilization alone is often insufficient to maintain the fractures as seen that despite K-wiring in this review the fractures still collapsed. The various factors responsible for this collapse are such as advanced age, substantial deformity of over $20^{\circ}$ dorsal tilt on lateral X-ray, or greater than $5 \mathrm{~mm}$ shortening by ulna variance on posteroanterior view, dorsal communition, fracture of the ulna, and displaced articular fractures $(42,43)$. Decision making in operative versus conservative treatment will be based on the balance of the above risks and benefits for each individual patient. The patient should be involved in decision process and be made to understand that none operative treatment of a displaced Colles fracture usually leads to deformity. Even after an excellent manipulation 
and reduction, gradual settling of unstable fractures is the rule. Intra-articular deformity accounts for the worst functional outcome (41).

The use of screws that lock to the plate via threads in the plate and thread in the screw head have greatly facilitated internal fixation of osteoporotic bones (43). Further suggestion of improving stability in osteoporotic bone fixation include hybrid pinning, external clumps $(44,45)$, use of bone graft and use of calcium phosphate cement $(46,47)$.

The fractures of the proximal tibial healed well with good results. However, two of the four ankle fractures were problematic, which were seen in elderly women, 75 and 85 years old had very poor bone quality and co-existing medical conditions. High incidence of complications (50\%) in these elderly patients after open reduction of fracture ankles has been reported (48, 49). The failure of internal fixation is due to decreased mechanical strength of the bones and its advised to use implants that minimise stress shielding of the bones such as screws, tensions band wiring and intramedullary pins and nails might be better choices than rigid plates. Use of bio-absorbable implants $(50,51)$ has been suggested and seen to give good results.

However, the risks of surgery in the elderly ankle with compromised soft tissue, poor vascular supply and multiple systemic disease, must be carefully evaluated. Bone grafting is advised and post operative splinting with well padded cast is useful (49).

There were 14 patients with vertebral fractures. They were all treated conservatively with supportive Dorsal Lumber Corsets, medication and physiotherapy. Vertebral fractures lead to pain and residual poor quality of life (52). Studies show that patients with vertebral fractures have reduction in quality of life equivalent to those of hip fractures (52). The spine is the most common site of osteoporotic fractures which lead to disability and morbidity (54-56). In this review the patients had prolonged hospital stay upto 34 days.

It is recommended this be treated by calcium, vitamin $\mathrm{D}$, biphosphonates, hormone replacement which are good in facilitating healing of the fractures. These fractures can complicate with eventual spinal stenosis which represents an enormous challenge to the spinal surgeon. The poor general health of the elderly patient and difficult technical problem of fixing osteoporotic bone are a dilemma. The use of Polymethylmethaacrylate (PMMA) or calcium apatite cement meant to reinforce bone seems optimal solution for injection into a single painful fracture vertebra or to assist reinforce multiple vertebrae to reinforce pedicle screws hold $(56,57)$. The pelvic, rib and sternal fractures healed eventually after 12 weeks but with residual pain and discomfort in the pelvis.

Osteoporosis is a preventable disease and in this regard there is growing evidence to suggest that physical exercises can prevent post-menopausal and age related bone loss (58).

Public education to create awareness of the disease and its consequences is mandatory so that preventive measures can be put in place. Widespread use of medications like vitamin D, calcium, biphosphonates, hormone replacement, SERM and calcitonin which have been shown in controlled studies to increase BMP and reduce fracture risks. Stopping smoking, alcohol intake and use of steroids can further decrease fracture risks in osteoporosis $(58,59)$.

It is recommended osteoporosis be included in orthopaedic curriculum in undergraduate and postgraduate level as it has been seen recently that many orthopaedic surgeons still neglect to identify, assess and treat osteoporosis $(60,61)$ appropriately.

In our developing country where BMD assessment is not easily available or too expensive, we recommend all patients over 75 years with fragility fractures be empirically treated for osteoporosis. This will help alleviate further fractures. It's important also to put preventive measures in place for the elderly patients to prevent falls, close supervision of the elderly and protective wear on their trochanters and knees. Further education for health care providers should be focused on Continuous Professional Developments (CPD) and seminars on osteoporosis (61) to include nurses to do surveillance for osteoporotic fractures (62) and we suggest Kenya Orthopaedic Association (K.O.A) should make osteoporosis guidelines as an outreach programme for the community.

\section{REFERENCES}

1. Consensus Development Conference. Prophylaxis and treatment of osteoporosis. Am. J. Med. 1991; 90:107-110.

2. Looker, A.C., Orwoll, E.S., Johnston, C.C. Jr., et al. Prevalence of low femoral bone density in older US adults from NHAnes III. J. Bone Miner. Res. 1997; 112:1761-1768.

3. World Health Organisation. Assessment of fracture risk and its application to screening for post menopausal osteoporosis. Technical Report Series. WHO, Geneva. 1994.

4. Melton, L. J. III. Epidemiology of fractures. In: Riggs B. L., Melton L. J. (eds): Osteoporosis: etiology; diagnosis and management, Raven Press, New York, pp 133-155. 1988. 
5. Nilsson, B.E. Age and incidence of ankle fractures. Acta. Orthop. Scand. 1969; 40:122-129.

6. Melton, L. J. III., Sampson, J. M., Morrey, B. F. and Illstrup, D.M. Epidemiologic features of pelvic fractures. Clin. Orthop. 1981; 155: 43-47.

7. Rose, S. H., Melton, L. J. III., Morey, B. F., et al. Epidemiologic features of humeral fractures. Clin. Orthop. 1982: 168: 24-30.

8. Seeley, D.G., Browner, W.S., Nevitt, M.C., et al. Which fractures are associated with low appendicular bone mass in elderly women? Ann. Intern. Med. 1991; 115: 837-842.

9. Barrios, C., Brostrom, L.A., Stark, A. and Walheim, G. Healing complications after internal fixation of trochanteric hip fractures: the prognostic value of osteopororsis. J. Orthop. Trauma. 1993; 7: 438-442.

10. Morrey, B.F., An, K.N. and Chao, E.Y. Functional evaluation of the elbow. In: Morrey BF (ed). The elbow and its disorders, $2^{\text {nd }}$ end. Saunders, Philadelphia, pp 86-97. 1993;

11. Cornell, C.N. Internal fracture fixation in patients with osteoporosis. J. Am. Acad. Orthop. Surg. 2003; 11:109-119.

12. Kim, W.Y., Han, C.H., Park, J.I. and Kim, J.Y. Failure of inter-trochanteric fracture fixation with a dynamic hip screw in relation to pre-operative fracture stability and osteoporosis. Int. Orthop. 2001; 25: 360-362.

13. Walsh, W.R., Sherman, P., Howlett, C.R., et al. Fracture healing in a rat osteopenia model. Clin. Orthop. 2001;218-227.

14. Cummings, S.R., Black, D.M. and Rubin, S.M. Lifetime risks of hip, Colle's, or vertebral fracture and coronary heart diseases among white postmenopausal women. Arch. Intern. Med. 1989; 149: 2445-2448.

15. Arrington, E.D., Smith, W.J., Chambers, H.G., et al. Complications of iliac crest bone graft harvesting. Clin. Orthop. 1996; 300-309.

16. Banwart, J.C., Asher, M.A. and Hassanein, R.S. Iliac crest bone graft harvest donor site morbidity. A statistical evaluation Spine. 1995; 20:1055-1060.

17. Summers, B.N. and Eisenstein, S.M. Donor site pain from the ilium. A complication of lumbar spine fusion. J. Bone Joint Surg. Br. 1989; 71: 677-680.

18. Lim, T.H., An H.S., Evanich, C., et al. Strength of anterior vertebral screw fixation in relationship to bone mineral density. J. Spinal Disord. 1995; 8: 121-125.

19. Kim, W.Y., Han, C.H., Park, J.I. and Kim, J.Y. Failure of inter-trochanteric fracture fixation with a dynamic hip screw in relation to pre-operative fracture stability and osteoporosis. Int. Orthop. 25: 360-362.

20. Sodergard, J., Sandelin, J. and Bostman, O. Mechanical failures of internal fixation in $T$ and $Y$ fractures of the distal humerus. J. Trauma. 1992; 33:687-690.
21. Dalen, N. and Jakobsson, B. Factors influencing the incidence of re-operation after femoral neck fractures. Int. Orthop. 1985; 9: 235-237.

22. Parker, M.J. Evidence based results depending on the implant used for stabilizing femoral neck fractures: Injury. 2002; 33(suppl 3): C15 - 18.

23. Blair, B., Koval, J.J., Kumar, et al. Basicervical fractures of the proximal femur. A biomechanical study of 3 internal fixation techniques: Clin. Orthop. 1994; 306: 256-263.

24. Bonnaire, F.A. and Weber, A.T. Analysis of fracture gap changes, dynamic and static stability of different osteosynthetic procedures in the femoral neck. Injury. 2002; 33(Suppl 3): C24-32.

25. Frankle, M.A., Heerscovici, D. Jr. DiPasquale, T.G., et al. A comparison of open reduction and internal fixation and primary total elbow arthroplasty in the treatment of intraarticular distal humerus fractures in women older than age 65. J. Orthop. Trauma. 2003; 17: 473-480.

26. Gambirasio, R., Riand, N., Stern, R. and Hoffmeyer, P. Total elbow replacement for complex fractures of the distal humerus: an option for the elderly patient. J. Bone. Joint. Surg. Br. 2001; 83: 974-978.

27. Muller, L.P., Dietz, S.O., Rommens, P.M. and Morrey, B.F. Total elbow replacement as primary treatment for complex fractures of the distal osteopenic humerus. Eur J. Trauma. 2003; 29: 63-67.

28. Pereles, T.R., Koval, K.J., Gallagher, M. and Rosen, H. Open reduction and internal fixation of the distal humerus functional outcome in the elderly. J. Trauma. 1997; 43: 578-584.

29. Waddell, J.P., Hatch, J. and Richards, R. Supracondylar fractures of the humerus: results of surgical treatment. J. Trauma. 1988; 28:1615-1621.

30. Jupiter, J.B., Neff, U., Holzach, P. and Allgower, M. Intercondylar fractures of the humerus: an operative approach. J. Bone Joint Surg. Am. 1985; 67: 226-239.

31. Ring, D. and Jupiter, J.B. Fractures of the distal humerus. Orthop. Clin. North Am. 2000; 31: 103-113.

32. Gupta, R. Intercondylar fractures of the distal humerus in adults. Injury. 1996; 27: 569-572.

33. Horne, G. Supracondylar fractures of the humerus in adults. J. Trauma. 1980; 20: 71-74.

34. Krotschek, H., Jhana, H. and Wittich, H. Fractures on the distal end of the upper arm. Hefte Unfallheilkd. 1973; 114:134-142.

35. Holdsworth, B.J. and Mossad, M.M. Fractures of the adult distal humerus. Elbow function after internal fixation. J. Bone Joint Surg. Br. 1990; 72: 362-365. 
36. Sodergard, J., Sandelin, J. and Bostman, O. Postoperative complications of distal humeral fractures. Acta. Orthop. Scand. 1992; 63:85-89.

37. John, H., Rosso, R., Neff, U., et al. Operative treatment of distal humeral fractures in the elderly. J. Bone Joint Surg. Br. 1994; 76: 793-796.

38. Ring, D., Perey, B. and Jupiter, J.B. The functional outcome of the operative treatment of un-united fractures of the humeral diaphysis in elderly patients. J. Bone Joint Surg. Am. 1999; 81:117-189.

39. John, H., Rosso, R., Neff, U., et al. Distal humerus fractures in patients over 75 years of age: long term results of osteoporosis. Helv. Chir. Acta. 1993; 60: 219-224.

40. Kocher, M., Melcher, G.A., Leutenegger, A. and Ruedi, T. Elbow fractures in elderly patients. Swiss. Surg. 1997; 3:167-171.

41. Young, B.T. and Rayan, G.M. Outcome following nonoperative treatment of displaced distal radius fractures in low-demand patients older than 60 years. J. Hand Surg. (Am). 2000; 25:19-28.

42. LaFontaine, M., Hardy, D. and Delince, P.H.Stability assessment of distal radius fractures. Injury. 1989; 20: 208-210.

43. Ring, D., Jupiter, J.B., Brennwald, J., Buchler, U. and Hastings, $\mathrm{H}$. Prospective multicenter trial of a plate for dorsal fixation of distal radius fractures. J. Hand Surg (Am). 1997; 22: 777-784.

44. Jupiter, J.B., Ring, D. and Weitzel, P.P. Surgical treatment of redisplaced fractures of the distal radius in patients older than 60 years. J. Hand Surg (Am). 2002; 27: 714-723.

45. Trumble, T.E., Wagner, W., Hanel, D.P., Vedder, N.B. and Gilbert, M. Intrafocal (Kapandi) pinning of distal radius fractures with and without external fixation. J. Hand Surg. (Am). 1998; 23: 381- 394.

46. Seitz, W.H., Froimson, A.L., Leb, R. and Shapiro, J.D. Augmented external fixation of unstable distal radius fractures. J. Hand Surg. (Am). 1991; 16: 1010-1016.

47. Cassidy, C., Jupiter, J.B., Cohen, M., et al. Noarian SRS cement compared with conventional fixation in distal radius fractures. A randomized study. J. Bone Joint Surg Am. 2003; 85: 2127-2137.

48. Court-Brown, C.M., McBirnie, J. and Wilson, G. Adult ankle fractures: an increasing problem. Acta. Orthop. Scand. 1998; 69: 43-47.

49. Beauchamp, C.G., Clay, N.R. and Thexton, P.W. Displaced ankle fractures in patients over 50 years of age. J. Bone Joint Surg. 1983; 65(B): 329-332.

50. Vijanen, J., Pihlajamaki, H., Kinnunen, J., Bondestan, S. and Rokkanen, P. Comparison of absorbable poly-L-lactide and metallic intramedullary rods in the fixation of femoral shaft osteotomies: an experimental study in rabbits. J. Orthop. Sci. 2001; 6: 160-166.
51. Karisson, J., Brandsson, S. and Moller, M. Ankle fractures In: Obrant K. (ed): Management of fracture in severely osteoporotic bone. Orthopaedic and pharmacological strategies. Springer, Berlin Heidelberg, New York, pp. 2000; 309-317.

52. Vevitt, M.C., Ettinger, B., Black, D.M., et al. The association of radiographically detected vertebral fractures with back pain and function: a prospective study. Ann. Intern. Med. 1998; 128: 793-800.

53. Hasserius, R., Karlsson, M. K., Nilsson, B. E., RedlundJohnell, L. and Johnell, O. Prevalent vertebral deformities predict increased mortality and increased fracture rate in both men and women: a 10 year population-based study of 598 individuals from the Swedish cohort in the European Vertebral Osteoporosis Study. Osteoporosis. Int. 2003; 14: 61-68.

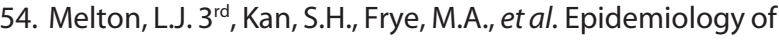
vertebral fractures in women. Am. J. Epidemiol. 1989; 129: 1000-1011.

55. Riggs, B.L. and Melton, L.J. $3^{\text {rd }}$. The worldwide problem of osteoporosis insights afforded by epidemiology. Bone. 1995; 17: 5055-5115.

56. Heini, P.F., Walchii, B. and Berlemann, U. Percutaneous transpedicular vertebroplasty with PMMA: Operative technique and early results. A prospective study for the treatment of osteoporotic compression fractures. Eur. Spine. J. 2000; 9: 445-450.

57. Heini, P.F. Vertebroplasty: the value of prophylactic augmentation. In: Szpalski M. Gunzburg R (eds) Vertebral osteoporotic compression fractures, 2003; pp 211-221.

58. Hochberg, M. Preventing fractures in postmenopausal women with osteoporosis. A review of recent controlled trials of antiresorptive agents. Drugs. Aging. 2000; 17: 317-330.

59. Bellantonio, S., Fortinsky, R. and Prestwood, K. How well are community-living women treated for osteoporosis after hip fracture? J. Am. Geriatr. Soc. 2001; 49: 1197-1204.

60. Castel, H., Bonneh, D.Y., Sherf, M. and Liei, Y. Awareness of osteoporosis and compliance with management guidelines in patients with newly diagnosed low-impact fractures. Osteoporos. Int. 2001; 12: 559-564.

61. Akesson, K., Dreinhofer, K.E. and Woolf, A.D. Improved education in musculoskeletal conditions is necessary for all doctors. Bull World Health Org. 2003; 81: 677-683.

62. McClellan, A., Fraser, M. and Brown, J. The Osteoporosisorthopaedic liaison nurse: a model for effecting secondary prevention of osteoporotic fractures in an orthopaedic and accident and emergency setting. J. Bone Miner. Res. 2000; 18 (Suppl 1): 5439. 